\title{
Flight activity of honey bee (Apis mellifera) drones
}

\author{
Maritza Reyes ${ }^{1}$, Didier Crauser ${ }^{1}$, Alberto Prado $^{2}$, Yves Le Conte ${ }^{1}$ \\ ${ }^{1}$ INRA, UR 406 Abeilles et Environnement, Laboratoire Biologie et Protection de l'abeille, Site Agroparc, Domaine St \\ Paul, 84914, Avignon, France \\ ${ }^{2}$ Escuela Nacional de Estudios Superiores, Unidad Juriquilla, UNAM, Querétaro, Mexico
}

Received 18 December 2018 - Revised 24 June 2019 - Accepted 5 July 2019

\begin{abstract}
Compared to the queen or the workers, the biology of honey bee Apis mellifera L. drones is poorly known. Available information on drone activity is based mainly on direct observations during a limited period of time and for a restricted time of the day. Complete registers of the flight activity of honey bee drones are lacking. We studied the activity of $A$. mellifera drones during their entire life in spring and summer by using an optical bee counter at the entrance of the hive. Drones were active in the afternoon, with most flights occurring between 14:00 and 18:00. Short orientation flights were performed at 6-9 days old, and longer mating flights of 30 min were performed from the age of 21 days onward during the spring and from the age of 13 days onward during the summer. Our registers show that 50 and $80 \%$ of the drones remained faithful to their colony (did not drift) in spring and summer, respectively. The present study confirms existing information, but also reveals unknown aspects about drone biology.
\end{abstract}

\section{drone / flight performance / longevity / behavioural development}

\section{INTRODUCTION}

Since the nineteenth century, the honey bee has been a very attractive model for sociobiology and behavioural sciences. Apis mellifera L. has been extensively studied, and among the different castes of the colony, scientists have focused mainly on the queen and workers and less on drone behaviour and biology. Even though drones do not participate in food collection or brood care, there are sophisticated interactions in which workers stimulate drones to perform trophallaxis by vibration signals (Slone et al. 2012; Goins and Schneider 2013). In addition, heat produced by drones is known to participate in the thermoregulation of the nest (Harrison 1987; Kovac et al.

Corresponding author: M. Reyes, maritza-regina.reyescarreno@inra.fr

Handling Editor: Monique Gauthier
2009). Drones have mainly received attention because of their astonishing mating behaviour outside the nest. Mature drones exit the nest and fly to specific drone congregation areas (DCAs) to mate with a queen. At $15-40 \mathrm{~m}$ in the air (Ruttner 1966), at the DCA, tens of thousands of drones congregate and wait for a queen. Copulation takes place on the wing and drones die shortly after mating (Koeniger et al. 2005a). Only a few studies have described the honey bee drone's flight activity and lifespan (Howell and Usinger 1933; Oertel 1956; Ruttner 1966; Witherell 1971; Hellmich 1991; Koeniger et al. 2005a; Koeniger et al. 2005b). Young individuals make orientation flights around the nest, before reaching sexual maturity some days later (Howell and Usinger 1933; Koeniger et al. 2005a). Orientation flights are a specific behaviour exhibited by bees that involve hovering back and forth at the entrance of the hive and then ascending in a spiralling flight. During these orientation flights, bees learn 
features of the landscape that allow them to return to the hive (homing) (Capaldi and Dyer 1999; Capaldi et al. 2000) and flight experience improves returning performance (Hayashi et al. 2017). According to Hellmich et al. (1991), the flight departure time of mature drones is around 16:00, with little variation between immature and mature drones. Under favourable weather conditions, drones can perform multiple mating flights in one afternoon, staying in the DCA for up to $30 \mathrm{~min}$ before returning to the hive to feed (Gary 1992). However, available information on drone flight behaviour is usually based on direct observations, during a limited period of time and only during limited time intervals (Burgett 1974; Fukuda and Ohtani 1977; Hellmich et al. 1991; Duay et al. 2002; Rueppell et al. 2005; Neves et al. 2011). Additionally, these observations cannot identify drones individually (Burgett 1974; Rueppell et al. 2005) and it is difficult to determine the exact number of drones that leave from or arrive at the hive, particularly when hundreds of drones fly at the same time (Rinderer et al. 1993). Furthermore, the time of flight can vary according to the weather conditions (Hellmich et al. 1991). Hence, the information that can be obtained by direct observation of drone flight behaviour is limited.

Drones can drift from one colony to another, and they are usually easily accepted into foreign colonies during the spring season. The drifting of drones is considered a common phenomenon in apiaries (Currie and Jay 1991; Moritz and Neumann 1996; Neumann et al. 2000), but empirical evidence of their fidelity to their own colony is lacking. In order to better understand honey bee drone behaviour and behavioural development of flight activity, we used an optical bee counter able to record exits and entrances of individually tag marked drones. We report on flight frequency and duration as well as drifting.

\section{MATERIAL AND METHODS}

Empty drone frames were introduced into a strong queen right colony to obtain emerging drones of the same age. The eggs laid by the queen developed into drones 25 days later. One hundred emerging drones $(0-12 \mathrm{~h}$ old $)$ from the same colony were individually marked with a distinctive tag numbered from 0 to 99 , glued to the thorax with the numbers in upright position (toward the head) (Figure 1). The tag allowed recording of the activity of each drone. Prior to this study, we confirmed that tags do not affect drone survival in laboratory conditions (data not shown). Tagged drones were introduced into an A. mellifera colony kept in a Dadant hive at INRA-Avignon (France). The hive consisted of 5 frames and about 10,000 workers. The apiary at INRA-Avignon consists of approximately 30 fullsize colonies and around 20 five-frame colonies. The experimental hive was placed at $20 \mathrm{~m}$ away from other colonies and between thick bushes to avoid drifting.

The activity of tagged drones leaving and entering the hive was registered using an optical bee counter based on a video camera recognition system and a passageway device that the drone must pass through in order to enter or exit the hive (Le Conte and Crauser 2006; Dussaubat et al. 2013; Alaux et al. 2014; Prado et al. 2019). The system continuously recorded the exit and entrance activity of the marked drones.

The optical bee counter consisted of a highresolution camera that monitored the hive entrance and an in-house image analysis software that detected and registered the tag. The software is able to detect the direction of the movement of the tag and discriminates exits from entrances. Identification of numbers is done by optical character recognition (OCR), considering the head as

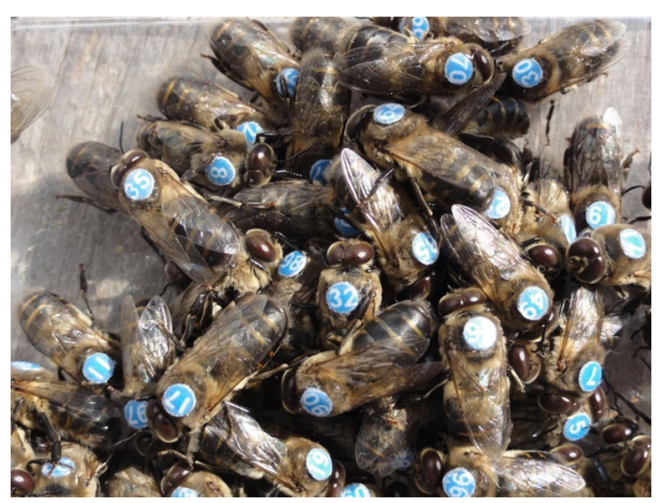

Figure 1. Tagged newly emerged drones before the experiments. 
up. For an entering drone, the image is turned $180^{\circ}$ before it is registered. The passageway device consists of five passages covered by Plexiglas, and a lighting system allows the camera to record. Images are analysed from 2 detection zones, and bees are counted only if they cross both zones. This limits the analysis to bees that are indeed leaving or returning to the hive.

Drone flights were defined as an exit-entrance sequence for a particular drone ID. Unpaired exits or entrances, due to undetected passages, were not taken into account (6\% of the data). Simultaneously, the optical counter records the global in-and-out activity of non-tagged workers of the hive. A 5-frame colony was chosen for this study to reduce the amount of traffic at the passageway and increase the accuracy of the recordings.

Two replicates were conducted over a 90-day period on the same hive, both with 100 drones. The first replicate was carried out during MayJune (spring) and the second during June-July (summer). In both cases, data were collected until the last drone left the hive.

Weather data (temperature, wind speed, rain) and times of sunrise and sunset were obtained over the two periods of the study from http://fr. weather.com/climate/sunRiseSunSet-AvignonFRXX0270 and http://www.infoclimat. fr/tableauX-station-meteo-avignon-07563. As drone activity peaked at 16:00 (see Section 3), correlation coefficients (Pearson's $r$ ) between drone activity (minutes spent outside the hive) and meteorological conditions at 16:00-17:00 were assessed via correlation tests using the cor. test function in $\mathrm{R}$.

To compare the drone activity (number of flights and total minutes spent outside the hive per day) between the spring and summer assays, we used the Mann-Whitney $U$ test as implemented in $\mathrm{R}$.

\section{RESULTS}

\subsection{Age of first and last flights}

A complete record of flights was obtained for 90 and 86 drones for spring and summer trials, respectively. In the spring, $74 \%$ of the individuals made their first flight at 6 days old, while in the summer, $51.7 \%$ made their first flight at 7 days old. The mean age at first flight was 5.6 days ( \pm $0.9 \mathrm{SD})$ and 7.2 days ( $\pm 0.5 \mathrm{SD})$, for spring and summer experiments, respectively.

The mean age at which drones performed their last flight in the spring was 17.9 days $( \pm 4.4 \mathrm{SD})$. In the summer, the last flight occurred significantly earlier than in the spring $\left(U=3347, N_{1}=90\right.$, $N_{2}=86, P=0.013$ ) on average at 15.2 days ( \pm 1.8 SD) (Table I). The maximum lifespans observed for spring and summer were 33 and 21 days, respectively (Table I).

\subsection{Orientation and mating flights}

As reported by other authors (Witherell 1971; Currie 1987), drones performed two types of flights in our experiments. Short flights (orientation) performed by young drones and longer flights (interpreted as mating flights when drones visit DCAs) performed later in life. During both trials, drones performed the short flights of about 15 min at ages 6-8 days during the spring trial (15.2 $\min \pm 10.1 \mathrm{SD})$ and at ages 7-9 days during the summer $(14.8 \mathrm{~min} \pm 11.8 \mathrm{SD})$. In the spring, longer mating flights of $31.5 \mathrm{~min}( \pm 11.4$ SD) were performed from the age of 21 days onward. During the summer trial, drones performed the long mating flights of $27.4 \mathrm{~min}$ ( \pm 14.5 SD) from 13 days old onward. The longest individual flight of a drone occurred in the spring at 28 days old ( $2 \mathrm{~h} 51 \mathrm{~min}$ ) and in the summer at 16 days old ( $1 \mathrm{~h} 45 \mathrm{~min})$. In both cases, this occurred during their last day flying.

Between the orientation and mating flights, despite favourable weather conditions, we observed a period of very low activity of 12 and

Table I. Age of the last registered flight for A. mellifera drones

\begin{tabular}{llr}
\hline & \multicolumn{2}{l}{ Drone age (days) } \\
\cline { 2 - 3 } & \multicolumn{1}{c}{ Mean $\pm \mathrm{SD}^{1}$} & Range \\
\hline Spring & $17.9 \pm 4.4 \mathrm{a}$ & $3-33$ \\
Summer & $15.2 \pm 1.8 \mathrm{~b}$ & $7-21$ \\
\hline${ }^{1}$ Different letters in the same column indicate significant dif- \\
ferences according to the Mann-Whitney $U$ test
\end{tabular}


5 days in spring and summer, respectively. During this period, drones rarely left the hive (Figure 2).

The time spent at DCAs (estimated as the total time of mating flights) averaged $510.9 \mathrm{~min}( \pm$ 268.5 SD) and $327.3 \mathrm{~min}( \pm 252.6 \mathrm{SD})$ in spring and summer, respectively. We found a positive relationship between the total time spent performing orientation flights and the total time spent at DCAs ( $r=0.31, P=0.003$, and $r=0.35$, $P=0.001$, spring and summer, respectively, Figure 3).

\subsection{Number of flights per day, flight days, lifetime flights and total flight time}

Drones performed $3.3( \pm 1.4)$ and $2.7( \pm 1.8)$ orientation flights per day during spring and summer, respectively. This amounted to a total of 8.8 $( \pm 3.3)$ and $8.1( \pm 3.1)$ orientation flights in the life of a drone, after which they mostly remained inside the hive until 21 days old in the spring and 14 days old in the summer, when they started performing longer flights (presumably mating flights where drones visit DCAs). In the spring, drones performed an average of $4.3 \pm 2.6$ mating flights per day. These mating flights were performed on average during $5.1 \pm 3.5$ nonconsecutive days, for a total of $22 \pm 14$ mating flights in the life of a drone in the spring. Drones flew more times per day in the summer trial $(U=$ $\left.18,792, N_{1}=224, N_{2}=212, P=0.0001\right)$ but on fewer days $\left(U=2016, N_{1}=46, N_{2}=70, P=\right.$ 0.02078; Table II). During the summer, they performed 5.7 mating flights per day during only 3.4 \pm 2 non-consecutive days, for a total of $20 \pm 19$ mating flights (Figure 4a).

Between mating flights, drones recharge themselves by eating honey (Witherel 1971; Currie

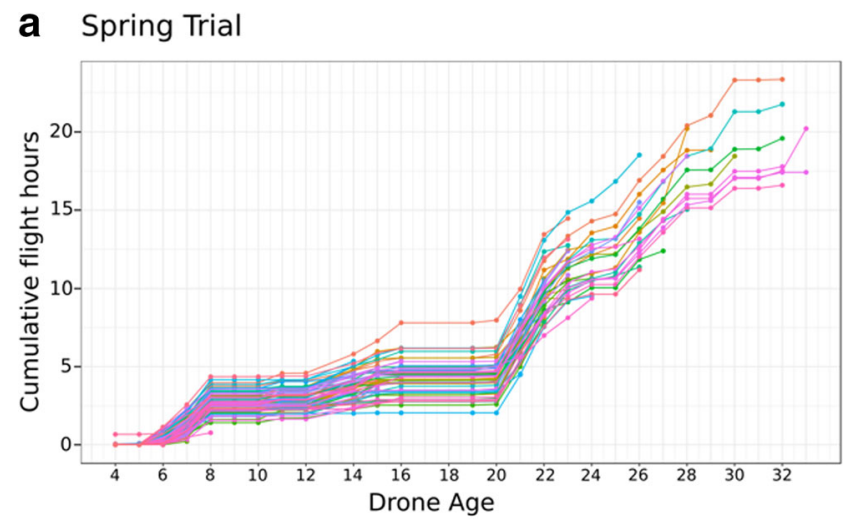

b Summer Trial

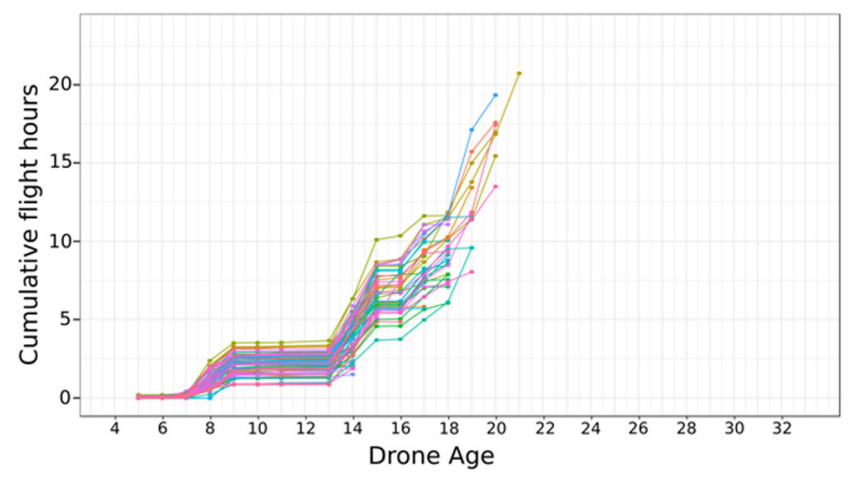

Figure 2. Cumulative time spent outside the hive by drones. a Spring trial. b Summer trial. Each coloured line represents one individual drone. 


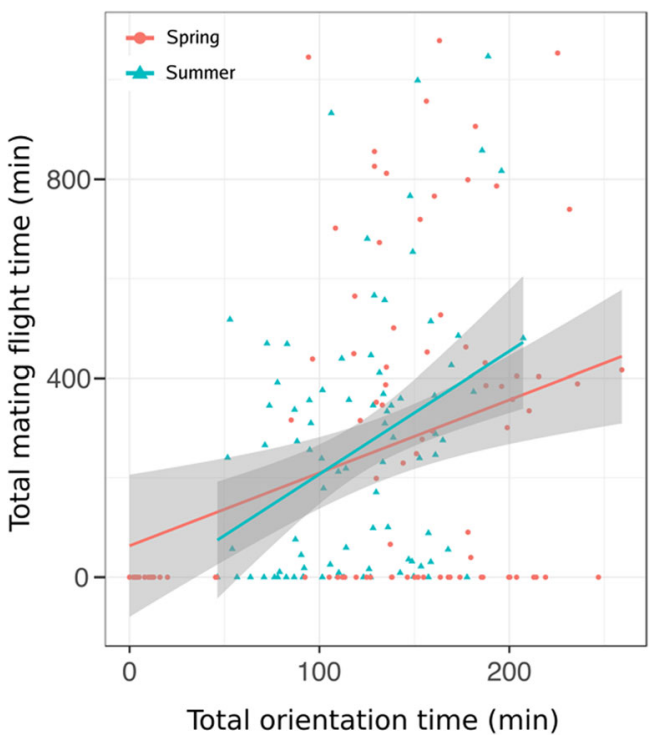

Figure 3. Time spent performing mating flights in relation to the time spent performing orientation flights ( $r=0.31, P=0.003$, and $r=0.35, P=0.001$, for spring and summer, respectively).

1987). In our study, drones spent $10.7 \pm 19.1$ and $14.7 \pm 24.7$ min (mean \pm SD) between mating flights inside the hive in the spring and summer, respectively (median of 3.8 and $3.3 \mathrm{~min}$ ) (Figure 4b).

The number of total flights per drone (orientation + mating) ranged from 1 to 106, with an average of $27.3 \pm 20.06$ and $27.4 \pm$ 21.5 flights in spring and summer, respectively. The high variability in total flights is partly explained by the percentage of drones

Table II. Total number of flight days for A. mellifera drones. Data are presented for drones with complete flight records (trial 1, $n=90$; trial 2, $n=86$ )

\begin{tabular}{lll}
\hline Trial & \multicolumn{2}{l}{ Total flight days } \\
\cline { 2 - 3 } & Mean $\pm \mathrm{SD}^{1}$ & Range \\
\hline Spring & $9.4 \pm 2.8 \mathrm{a}$ & $1-14$ \\
Summer & $7.2 \pm 1.5 \mathrm{~b}$ & $1-22$ \\
\hline
\end{tabular}

${ }^{1}$ Different letters in the same column indicate significant differences according to the Mann-Whitney $U$ test that did not live long enough to perform mating flights; $48 \%$ and $19 \%$, in spring and summer, respectively, did not perform a single mating flight. The total number of flights per drone was not different between the two evaluated seasons $\left(U=3890, N_{1}=90, N_{2}=\right.$ $86, P=0.954)$. Nor was the cumulative time of flight $\left(U=4241, N_{1}=90, N_{2}=86, P=\right.$ 0.2728 ) with an average of $7 \mathrm{~h} 37 \mathrm{~min} 37 \mathrm{~s}$ in spring and $6 \mathrm{~h} 19 \mathrm{~min} 27 \mathrm{~s}$ in summer (Table III).

\subsection{Flight period}

In both trials, the earliest registered flights of sexually mature drones were at 7:00 although these were very rare events (Figure $5 \mathrm{a}, \mathrm{c}$ ). In general, drones began their flights during the afternoon (Figure 5a, c) and most daily flights occurred between 14:00 and 18:00, with a marked peak of activity at 16:00 (Figure 5b, d). In the summer, the time length for outdoor activity was $3 \mathrm{~h}$ longer than in the spring $\left(U=4724, N_{1}=237\right.$, $\left.N_{2}=240, P=0.0135\right)$, meaning that some drones began to fly earlier and came back later to their hive.

Low but significant correlations were observed between sunrise and the daily start time of the drones' flights $(r=0.394, P=0.0335$, and $r=-$ $0.611, P=0.0104$, for trial 1 and trial 2 , respectively), and between the length of the day and the start time of drone flights $(r=-0.401, P=$ 0.0303 , and $r=0.687, P=0.0024$, for trial 1 and trial 2 , respectively).

Drones were not constantly active throughout their lives. On the contrary, we observed peaks of activity (Figure 6). The first peak in activity occurred almost at the same age (69 days old) in both trials, corresponding to orientation flights (Burgett 1974; Capaldi and Dyer 1999; Capaldi et al. 2000). Later bouts in activity occurred once drones attained an age of sexual maturity and were predominantly associated with favourable climatic conditions allowing for mating flights (Figure 6). However, despite favourable weather conditions, on some occasions, drones remained inside the hive after two days of performing mating flights. 

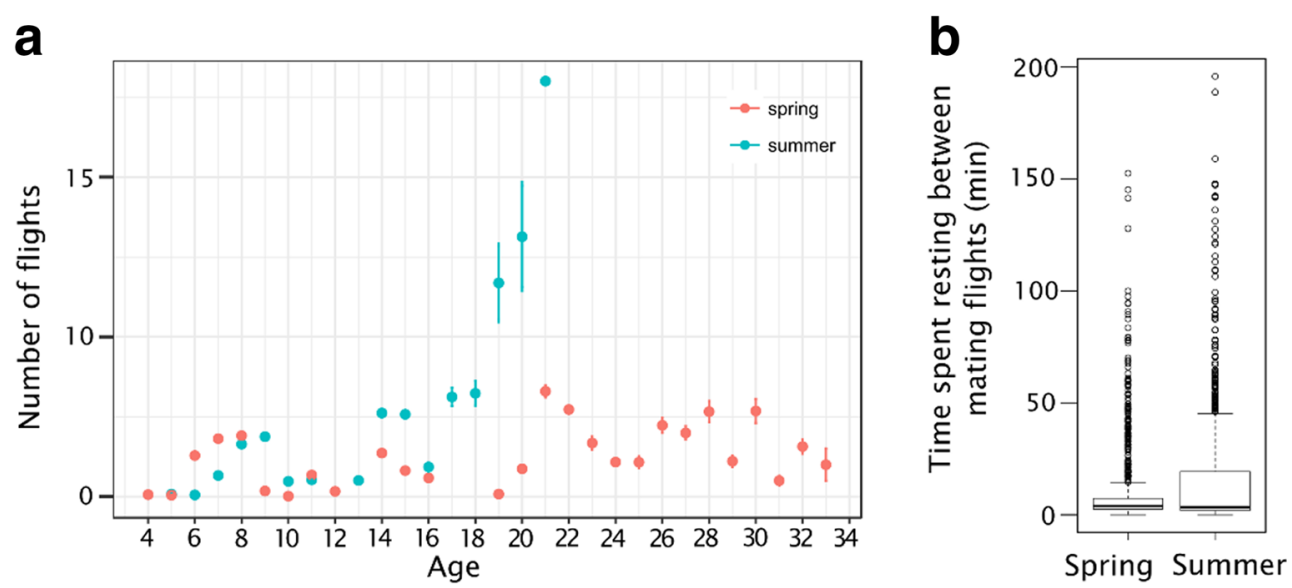

Figure 4. Number of flights and time spent resting. a Average number of flights performed by drones depending on their age. Only round trips (exit-entrance sequence) are represented. b Time spent by drones in the colony between two mating flights in spring and summer trials.

\subsection{Effects of weather conditions on drone flights}

According to our observations, drones rarely went out of the hive if wind speed reached $30 \mathrm{~km} / \mathrm{h}$ or when it was raining (only 2 rain events occurred in the spring and none in the summer). However, a few drones were able to fly on days when wind reached $35 \mathrm{~km} / \mathrm{h}$. These drones made several short flights (from $30 \mathrm{~s}$ to $7 \mathrm{~min}$ ) during the day, while most drones waited until the wind speed descended below $30 \mathrm{~km} / \mathrm{h}$ to start their flights (Figure 6). Temperature at 16:00 was correlated with drone activity in the spring but not in the summer when daily temperatures remained above $19{ }^{\circ} \mathrm{C}$ (Table IV). During the summer, drones continued to make mating flights one hour later in the afternoon than during the spring (Figure 5).

\subsection{Returning to the hive and drifting}

The optical counter data were used to estimate how many drones drifted into other colonies by assessing the number of drones that spent one or several nights elsewhere before returning. This measure will underestimate drone drifting as it cannot account for drones that drift permanently into other colonies. During the spring trial, 7 drones $(7.7 \%)$ drifted into other colonies and came back 1-13 days later, while 46 (50.5\%) remained faithful to their colony. Three drones died inside the hive (last detected entering the hive) and $35(38.5 \%)$ could potentially have drifted to other colonies and never returned, or died outside the hive before the onset of mating flights. During the summer trial, three drones $(3.5 \%)$ drifted into other colonies and came back 1-6 days later, while $70(80 \%)$ remained faithful to their colony until mating flights started

Table III. Total flight time (h:min:s) and lifetime flights for A. mellifera drones. Data are presented for drones with complete flight records (trial 1, $n=90$; trial 2, $n=86$ )

\begin{tabular}{llllll}
\hline Trial & \multicolumn{2}{l}{ Total flight time (h:min:s) } & & & \multicolumn{2}{l}{ Total lifetime flights } \\
\cline { 2 - 3 } & Mean \pm SD & & & Mean \pm SD & Range \\
\hline Spring & $07: 37: 37 \pm 03: 09: 18$ & $00: 03: 00-23: 38: 04$ & & $27.3 \pm 8.9$ & $2-95$ \\
Summer & $06: 19: 27 \pm 02: 30: 31$ & $00: 32: 13-20: 35: 55$ & & $25.8 \pm 8.2$ & $2-85$ \\
\hline
\end{tabular}


a

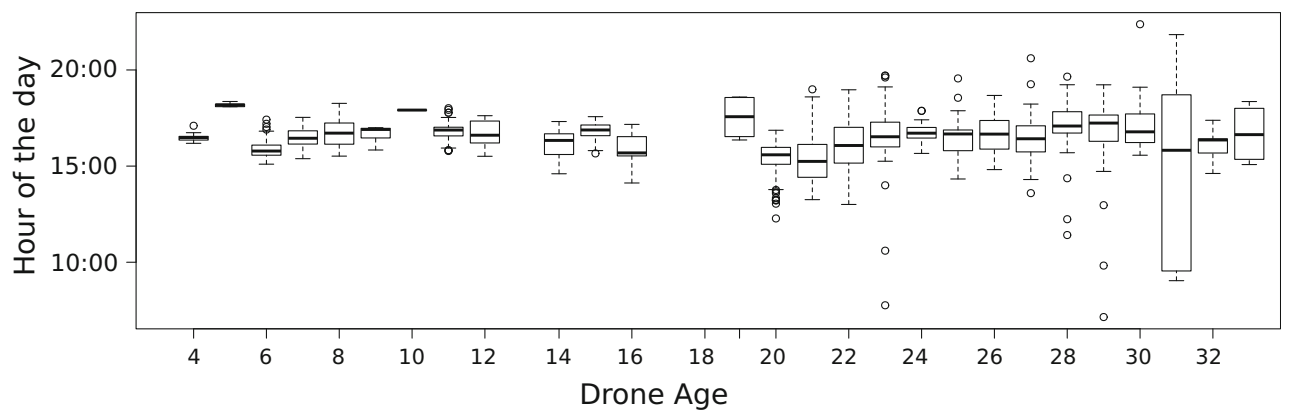

b

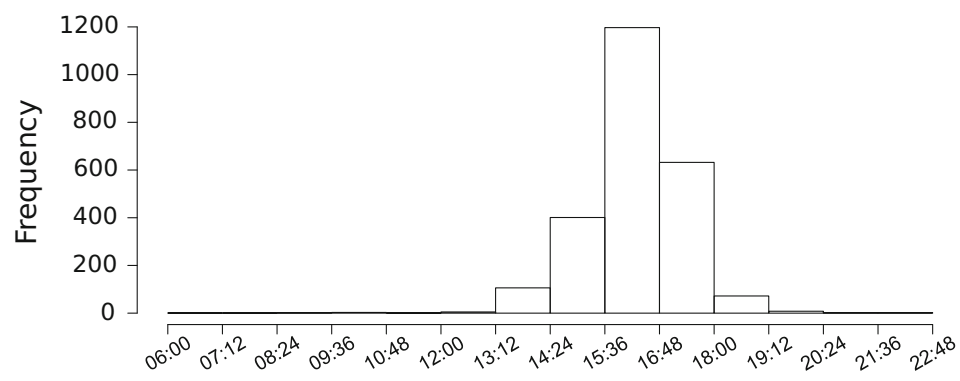

Hour of the day

C
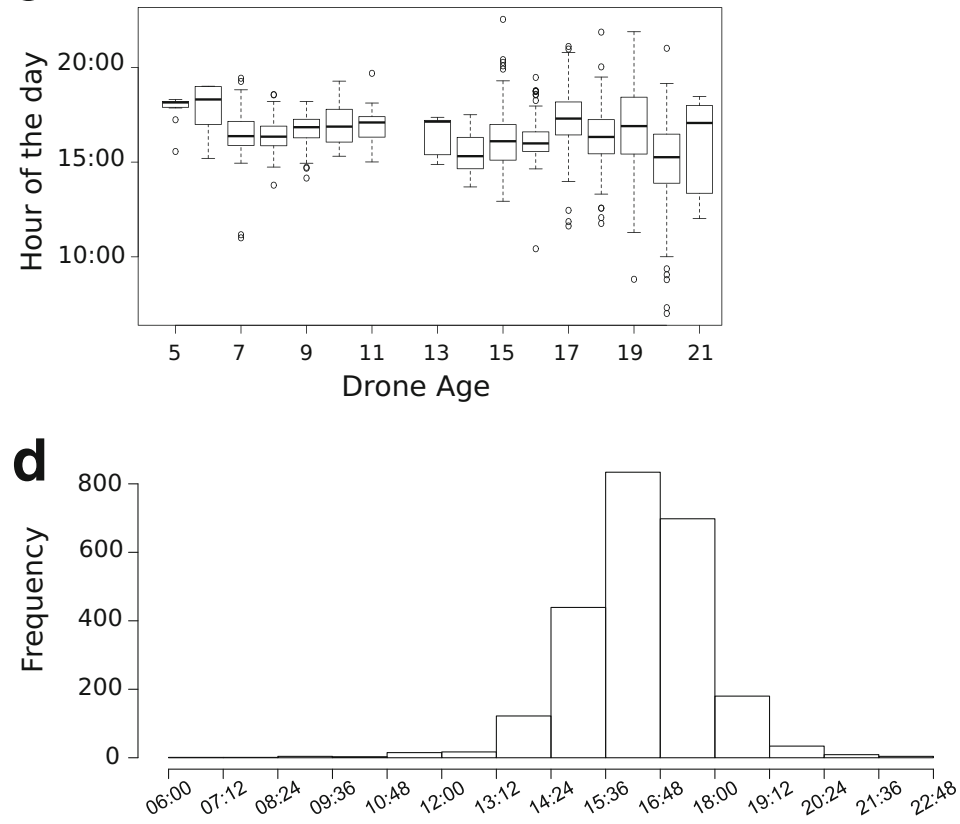

Hour of the day

Figure 5. Hour of the day of Apis mellifera drone activity. a Hour at which drones left the hive in the spring in relation to their age. $\mathbf{b}$ Histogram of hour of exit during the spring experiment (mean $=16: 16$ ). $\mathbf{c}$ Hour at which drones left the hive in the summer in relation to their age. $\mathbf{d}$ Histogram of hour of exit during the summer experiment $($ mean $=16: 21)$. 

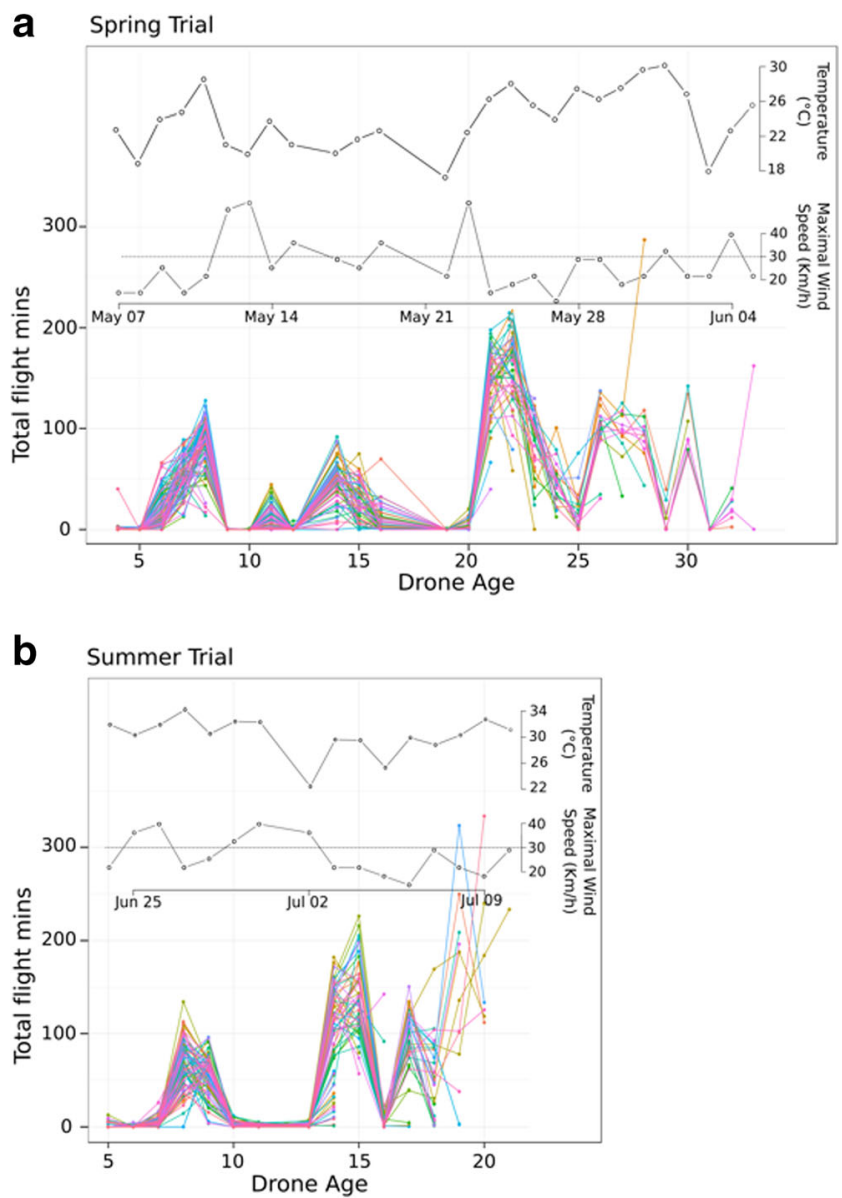

Figure 6. Daily activity of drones during the spring (a ) and summer (b) experiments. Insert on graphs represents temperature and maximum wind speed between 16:00 and 17:00. Dashed lines represent the maximum wind speed that prevented drone flight $(30 \mathrm{~km} / \mathrm{h})$.

Table IV. Correlation coefficients (Pearson's $r$ ) between drone activity (minutes spent outside the hive) and meteorological conditions at 16:00-17:00

\begin{tabular}{llc}
\hline & Spring & Summer \\
\hline Temperature & 0.62 & 0.01 \\
Precipitation & -0.21 & - \\
Maximal wind speed & -0.43 & -0.44 \\
Mean wind speed & -0.40 & -0.37 \\
Thermal amplitude & 0.44 & 0.23 \\
Global radiation & 0.36 & 0.13 \\
\hline
\end{tabular}

Italicised numbers indicate significant correlations
(14 days). Four drones died inside the hive and 10 $(11.5 \%)$ could potentially have drifted to other colonies and never returned, or died outside the hive before reaching sexual maturity (Figure 7).

\subsection{Drone and worker bee flights}

We observed a daily activity peak in worker and drone flights, but we did not find a clear relationship between the daily peak in drone activity (16:00) and the afternoon worker bee peak. While bee males remained constant in their 16:00 peak in activity (Figure 5), the peak in activity of bee workers was different 


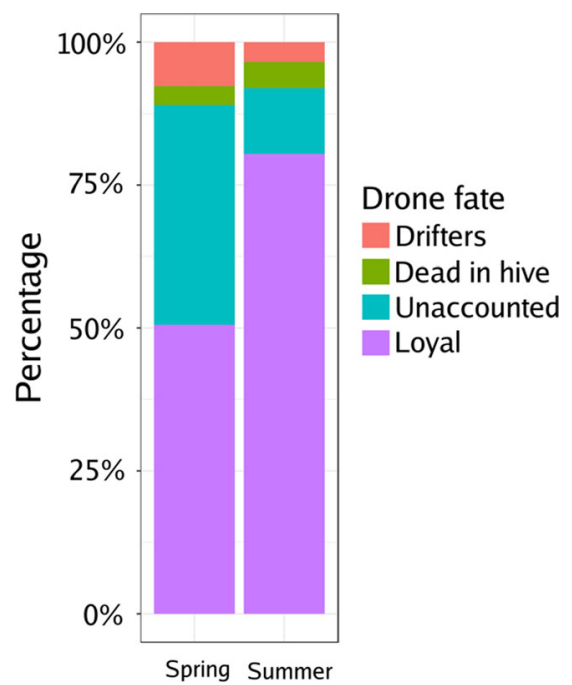

Figure 7. Drone fate. Drones were considered drifters if they spent one or more days outside the hive and returned. Unaccounted drones left the hive before sexual maturity and never returned.

each day and seemed to be more sensitive to changes in weather conditions (Figure 8).

\section{DISCUSSION}

We recorded lifetime flight activity of honey bee drones, confirming available reports (Burgett 1974; Hellmich et al. 1991; Neves et al. 2011), but also providing novel information in relation to drone age and meteorological conditions. Drones started performing orientation flights at 6-7 days of age as reported previously (Tozetto et al. 1997; Colonello-Frattini and Hartfelder 2009). The age of the last drone that abandoned the hive (21 and 33 days) also corresponded to previously published data (Winston 1987).

In this study, longevity was estimated as the time of the last recording. We observed longerlived drones in the spring as opposed to the summer. Fukuda and Ohtani (1977) also detected a difference between lifespan of drones in different seasons (autumn and summer), with the autumn drones living longer. In both cases, the life of bee males was shorter in the summer, which could be related to the higher temperatures and to the number of mating flights performed per day. In our study, the average temperature during the spring

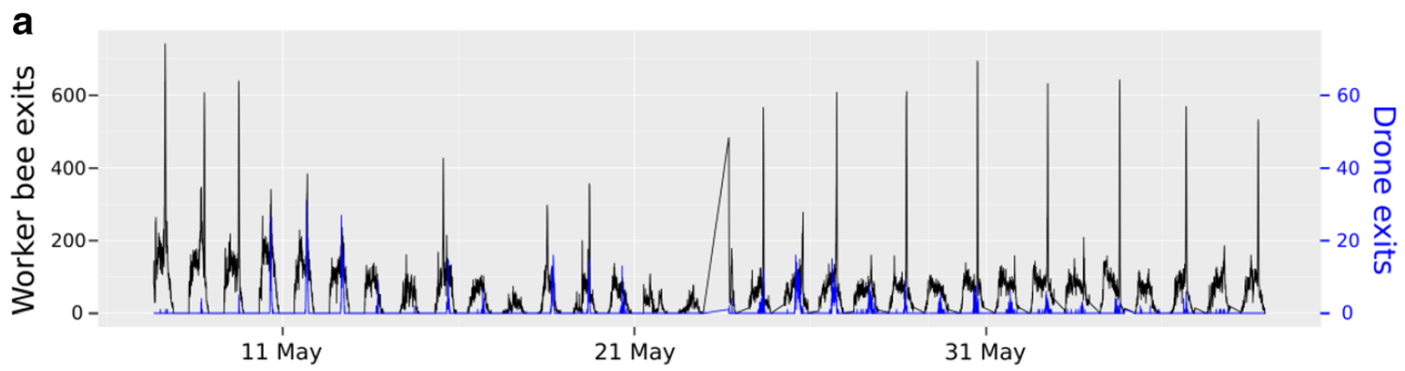

b
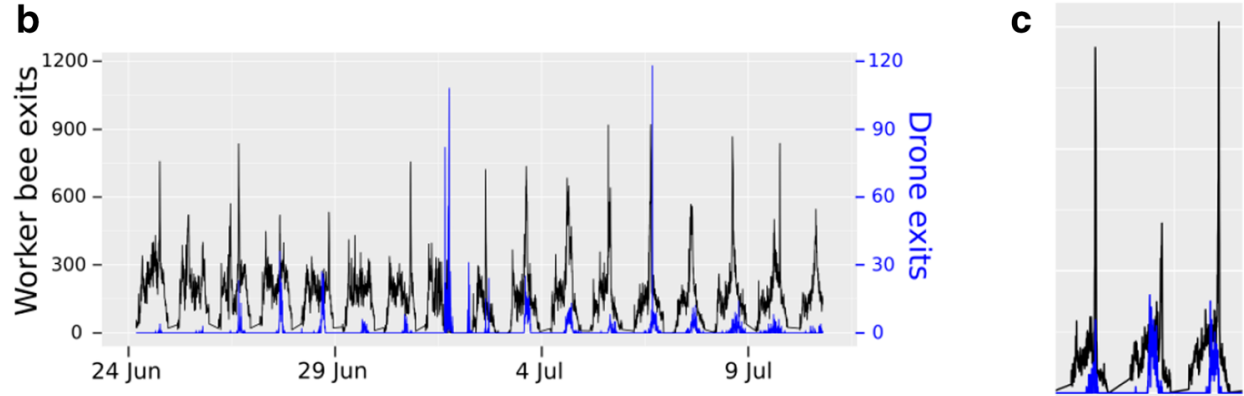

Figure 8. Worker and drone daily activity. Black lines represent the number of workers exiting the hive. Blue lines represent the number of drones leaving the hive. While on some days, the afternoon peak activity of drones (16:00) coincided with the peak in activity of workers, on other days, drone peak activity preceded that of workers. 
was $5.2{ }^{\circ} \mathrm{C}$ lower than during the summer. In the summer, the period of the day during which drones were active was increased by $3 \mathrm{~h}$, and mating flights increased from 4.3 to $5.7 \mathrm{~h}$ per day. Rowell et al. (1986) indicate that high mortality in the summer is probably related to both high levels of flight activity and meteorologically extreme conditions, associated with resource stress on the colony. In our summer trial, longevity reached only 15.2 days. This value is similar to the results of Fukuda and Ohtani (1977), who determined survival by counting the number of marked drones that returned to the hive. Other studies, however, indicate that the longevity of summer drones would be between 21.2 and 23.5 days (Witherell 1972).

In both trials, we observed the onset of mating flights to be associated with increases in daily temperatures (Figure 6). Interestingly, in both trials, after two days of performing mating flights, drones stayed inside the hive, only to continue flying one or two days later, which appear as peaks of activity in Figure 6. This pause in activity does not seem to be associated with the climatic conditions in the summer trial as the weather conditions were good for flight. Hence, the pause in activity could reflect a physiological constraint.

We found a weak but significant positive relationship between the time spent performing orientation flights and the time spent on mating flights. Drones that spent more time on orientation also spent more time at the DCAs (as estimated by mating flight time). This relationship could reflect the greater flight capacity of certain individuals or the importance of learning through orientation flights (Capaldi and Dyer 1999; Capaldi et al. 2000). Manipulative studies that limit the orientation time for drones could shed light on the role of learning on drone performance.

The wind had an important effect on drone flight. While we found that most drones did not fly on days when the wind was $>30 \mathrm{~km} / \mathrm{h}$, independent of their age, Lensky and Dempter (1985) observed delayed queen and drone flights when the wind was $>14 \mathrm{~km} / \mathrm{h}$. Similarly, Duay et al. (2002) indicated that bee males do not fly when the wind exceeds $15 \mathrm{~km} / \mathrm{h}$. In the present study, some drones accomplished several short flights when the average wind speed was up to
$35 \mathrm{~km} / \mathrm{h}$, which suggests that the queen could be more sensitive to the wind than drones and that better-performing drones would be more competitive for mating with the queen. We also observed that after a windy day, when drones did not leave the hive, they had a short flight early in the morning on the next day. Short flights on windy days or early in the morning could be hygienic flights (Page and Peng 2001).

We found that drone activity does not exclusively occur in the afternoon as suggested by earlier investigations (Burguett 1974; Fukuda and Ohtani 1977; Hellmich et al. 1991; Duay et al. 2002; Rueppell et al. 2005). According to the weather conditions, some males flew early in the morning (7-9 h) or late in the evening (19$22 \mathrm{~h}$ ). We also observed that summer drones began and finished their daily flights later than spring drones. A. mellifera queens take nuptial flights between 12:00 and 17:00 with a maximum flight activity between 13:00 and 16:00 (Heidinger et al. 2014). Lensky and Demter (1985) observed that the duration of queen flights was reduced at temperatures of 15 and $20^{\circ} \mathrm{C}$. This was confirmed by Heidinger et al. (2014) that reported that queens fly less often but during longer periods at high temperatures compared to lower temperatures. Ideally, organisms should time their activities in a fitness-maximizing manner; hence, the peak in drone activity at 16:00 could reflect this optimisation.

Drones can be accepted into different hives when the conditions are favourable (weather and food availability) (Galindo-Cardona et al. 2015). According to Jaffé and Moritz (2010), drone drift of $A$. mellifera can reach $10 \%$ of drones within the hive. This value is in agreement with our observations, as 7 and $4 \%$ of the drones were confirmed drifters (drones that came back after spending one or more nights outside the hive). Additionally, a fraction of the drones that left the hive and never came back could have potentially drifted into other colonies (these drones were considered as unaccounted in Figure 7) (Fukuda and Ohtani 1977). In our study, 50 and $77 \%$ of the spring and summer drones, respectively, remained faithful to their colony until the onset of mating flights. 
As reported by Woyke et al. (2001) for Apis dorsata, we also found a negative correlation between sunrise time and the start of drone flight. However, in our study, the level of correlation was lower possibly due to the shorter amplitude in the variation of the sunrise time. While the authors observed a one hour difference between the first and the last date of their study, in the present study, this difference was only $39 \mathrm{~min}$ in the summer trial.

Drones are reported to fly at speeds of 9$11.5 \mathrm{~km} / \mathrm{h}$ (Gmeinbauer and Crailsheim, 1993; Koeniger et al. 2005a). DCAs have been reported to occur at close proximity to apiaries, with a maximum distance reported of $7 \mathrm{~km}$ (Ruttner and Ruttner, 1972). Considering that we recorded an average flight length of $30 \mathrm{~min}$, most drones must have been visiting congregation areas at a distance of $2-4 \mathrm{~km}$ from the hive. Very few flights exceeded $60 \mathrm{~min}$, and the longest flight we recorded was $171 \mathrm{~min}$ long. These rare long flights could be associated with drones visiting DCAs at longer distances, staying in the DCA for a longer time, or going to another colony between two mating flights (Galindo-Cardona et al. 2015).

Optical bee counters are useful tools that permit the study of the behaviour of hundreds of individual bees. We have provided detailed information on the flight behaviour and outdoor activity of drones, regarding the time of day of their activity and the number and duration of flights. We observed that most drones remained faithful to their colony until the onset of mating flights.

Drones are social beings, and their mating activities should be considered in relation to the colony (Ruttner 1966). In this study, we used a small 5-frame hive; the small size of the colony could have an effect on drone activity. In order to confirm our findings, future studies using full-size colonies are needed.

\section{AUTHOR CONTRIBUTIONS}

MR and DC conceived, designed and performed the experiments; MR and AP analysed the results; MR wrote the original draft; AP and YLC edited the draft and participated in data interpretation. All of the authors approved the final version.
Activité de vol des abeilles mâles (Apis mellifera)

mâle / performance en vol / longévité / développement comportemental

Flugaktivitát von Drohnen der Honigbiene (Apis mellifera )

\section{Drohne / Flugleistung / Lebensdauer / Verhaltensentwicklung}

\section{REFERENCES}

Alaux, C., Crauser, D., Pioz, M., Saulnier, C., Le Conte, Y. (2014) Parasitic and immune-modulation of flight activity in honey bees tracked with optical counters. J. Exp. Biol. 217, 3416-3424.

Burgett, M. (1974) Drone honey bee flight from clustered swarms. Ann. Entomol. Soc. Am. 67, 683-684.

Capaldi, E.A., Dyer, F.C. (1999) The role of orientation flights on homing performance in honeybees. J. Exp. Biol. 202, 1655-1666.

Capaldi, E.A., Smith, A.D., Osborne, J.L., Fahbach, S.E., Farris, S.M., Reynolds, D.R., Edwards, A.S., Martin, A., Robinson, G.E., Poppy, G.M., Riley, J.R. (2000) Ontogeny of orientation flight in the honeybee revealed by harmonic radar. Nature 403, 537-540.

Colonello-Frattini, N., Hartfelder, K. (2009) Differential gene expression profiling in mucus glands of honey bee (Apis mellifera) drones during sexual maturation. Apidologie 10, 481-495.

Currie, R W. (1987) The biology and behaviour of drones. Bee World 68, 129-143.

Currie, R.W. and Jay, S.C. (1991) Drifting behaviour of drone honey bees (Apis mellifera L) in commercial apiaries. J. Apic. Res. 30, 61-68.

Duay, P., De Jong, D., Engels, W. (2002) Decreased flight performance and sperm production in drones of the honey bee (Apis mellifera) slightly infested by Varroa destructor mites during pupal development. Genet. Mol. Res. 1, 227-232.

Dussaubat, C., Maisonnasse, A., Crauser, D., Beslay, D., Costagliola, G., Soubeyrand, S., Kretzchmar, A., Le Conte, Y. (2013) Flight behavior and pheromone changes associated to Nosema ceranae infection of honey bee workers (Apis mellifera) in field conditions. J. Invert.Pathol. 113, 42-51.

Fukuda, H., Ohtani, T. (1977). Survival and life span of drone honeybees. Res. Popul. Ecol. 19, 51-68.

Gary, N.E. (1992) Activities and behaviour of honey bees. In: Graham JM (Ed.), The hive and the honey bee. Dadant \& Sons Inc., Hamilton, pp. 269-372. 
Goins, A., Schneider, S.S. (2013) Drone "quality" and caste interactions in the honey bee, Apis mellifera L. Insectes Soc. 60, 453-461.

Gmeinbauer, R., Crailsheim, K. (1993) Glucose utilization during flight of honeybee (Apis mellifera) workers, drones and queens. J. Insect Physiol. 39, 959-967.

Harrison, J.M. (1987) Roles of individual honeybee workers and drones on colonial thermogenesis. J. Exp. Biol. 129, 53-61.

Hayashi, S., Farkhary S., Takata, M., Satoh, T., Koyama, S. (2017) Return of drones: Flight experience improves returning performance in honeybee drones. J. Insect Behav. 30 (3), 237-246.

Heidinger, I.M.M., Meixner, M.D., Berg, S., Büchler, R. (2014) Observation of the mating behavior of honey bee (Apis mellifera L.) queens using radio-frequency identification (RFID): factors influencing the duration and frequency of nuptial flights. Insects 5, 513-527.

Hellmich, R.L., Rinderer, T.E., Danka, R.G., Collins, A.M., Boykin, D.L. (1991) Flight times of Africanized and European honey bee drones (Hymenoptera: Apidae). J. Econ. Entomol. 84, 61-64.

Howell, D.E., Usinger, R.L. (1933) Observations on the flight and length of life of drone bees. Ann. Entomol. Soc. Am. 26, 239-246.

Jaffé, R.,Moritz, R. (2010) Mating flights select for symmetry in honeybee drones (Apis mellifera). Naturwissenschaften 97, 337-343.

Koeniger, N., Koeniger, G., Gries, M., Tingek, S. (2005a) Drone competition at drone congregation areas in four Apis species. Apidologie 36, 211-221.

Koeniger, N., Koeniger, G., Pechhacker, H. (2005b) The nearer the better? Drones (Apis mellifera) prefer nearer drone congregation areas. Insect Soc. 52, 31-35.

Kovac, H., Stabentheiner, A., Brodschneider, R. (2009) Contribution of honeybee drones of different age to colonial thermoregulation. Apidologie, 40, 82-95.

Le Conte, Y., Crauser, D. (2006) Vers de nouveaux systèmes de comptages automatiques d'abeilles. Bull. Tech. Apic. 33, 23-30.

Lensky, Y., Demter, U. (1985) Mating flight of the queen honeybee (Apis mellifera) in a subtropical climate. Comp. Biochem. Physiol. 81A, 229-241.

Moritz, R.F.A., Neumann, P. (1996) Genetic analysis of the drifting of drones in Apis mellifera using multilocus DNA fingerprinting. Ethology 102 (7), 580-590.

Neumann, P., Moritz, R.F.A., Mautz, D. (2000) Colony evaluation is not affected by drifting of drone and worker honeybees (Apis mellifera $\mathrm{L}$.) at a performance testing apiary. Apidologie 31, 67-79.

Neves, E., Faita, M., de Oliveira Gaia, L, Vieira Alves Júnior, V., Antonialli-Junior, F. (2011) Influence of
Climate Factors on Flight Activity of Drones of Apis mellifera (Hymenoptera: Apidae). Sociobiology 57,107-111.

Oertel, E (1956) Observation on the flight of drone honey bees. Ann. Entomol. Soc.Am. 49, 497-500.

Page, R., Peng, C. (2001) Aging and development in social insects with emphasis on the honey bee, Apis mellifera L. Exp. Gerontol. 36, 695-711.

Prado, A., Pioz, M., Vidau, C., Requier, F., Jury, M., Crauser, D., Brunet, J-L., Le Conte, Y., Alaux, C. (2019) Exposure to pollen-bound pesticide mixtures induces longer-lived but less efficient honey bees. Sci. Total Environ. 650, 1250-1260.

Rinderer, T., Oldroyd B, Wonsiri, S., Allen Sylvester, H., De Guzman L, Potichot, S. Sheppard, W., Buckmann, S (1993) Time of drone flight in four honey bee species in south-eastern Thailand. J. Apic. Res. 32 (1), 27-33.

Rueppell, O., Fondrk, M.K. and Page, R.E. (2005) Biodemographic analysis of male honey bee mortality. Aging cell 4, 13-19.

Ruttner, H. (1966) The Life and Flight Activity of Drones. Bee World 47 (3), 93-100.

Ruttner, H., Ruttner, F. (1972). Untersuchungen über die Flugaktivität und das Paarungsverhalten der Drohnen. V.-Drohnensammelplätze und Paarungsdistanz. Apidologie, 3, 203-232.

Rowell, G.A., Taylor, O.R., Locke, S.J. (1986) Variation among commercial honey bee stocks. Apidologie $17(2), 137-158$.

Slone, J.D., Stout, T.L., Huang, Z.Y., Schneider, S.S. (2012) The influence of drone physical condition on the likelihood of receiving vibration signals from worker honey bees, Apis mellifera. Insectes Soc. 59, 101-107.

Tozetto, S., Rachinsky, A., Engels, W. (1997) Juvenile hormone promotes flight activity in drones (Apis mellifera carnica). Apidologie 28, 77-84.

Winston, M. (1987) The biology of the honey bee. Cambridge, Harvard Univerty Press. 276 p.

Witherell, P.C. (1971) Duration of flight and interflight time of drone honey bees, Apis mellifera. Ann. Entomol. Soc. Am. 64 (3), 609-612.

Woyke, J., Wilde, J., Wilde, M. (2001) Apis dorsata drone flights, collection of semen from everted endophalli and instrumental insemination of queens. Apidologie 32, 407-416.

Publisher's note Springer Nature remains neutral with regard to jurisdictional claims in published maps and institutional affiliations. 